\title{
Sounding Mathematics: How Integrating Mathematics and Music Inspires \\ Creativity and Inclusion in Mathematics Education
}

\author{
Caroline Hilton and Markus Cslovjecsek
}

The workshop focused on the principles underpinning our integrated approach to the teaching of mathematics and music, within the context of "low threshold, high ceiling" tasks. Participants engaged with a number of activities from the Comenius Project "EMP-M - Sounding Ways into Mathematics" (2013-2016). By actively participating in the activities, participants were enabled to experience the mathematical relationships and patterns through the music, thus reinforcing the interconnectedness of the two disciplines. Following the ideas of Barnes (2015), we explored the notion of integrated teaching as "interdisciplinary", rather than, for example, hierarchical or opportunistic.

It is worth briefly reflecting on why this interconnectedness between music and mathematics is so attractive. According to Leone Burton, mathematical thinking "is mathematical not because it is thinking about mathematics, but because the operations on which it relies are mathematical operations" (Burton 1984, p. 36). Citing Hofstadter (1979), Burton suggests that mathematical thinking relies on pattern recognition, iteration and repetition; processes found not only in mathematics, but also in music and art, for example in the works of Bach and Escher, to name but two. Learning mathematics, according to this definition, would require children to explore mathematical questions and relationships in messy and often haphazard ways, in attempts to make sense of what they find. For this reason, exploring mathematics and music together, in an interconnected way, where it is hard to identify where the music ends and the mathematics begins, for instance, seems to make sense. What we have found is that while the language of mathematics and music and their representations are different, when we look for similarities we see that we can often make direct translations.

\footnotetext{
C. Hilton ( $\square)$

UCL Institute of Education, London, UK

e-mail: c.hilton@ioe.ac.uk

(C) The Author(s) 2017

G. Kaiser (ed.), Proceedings of the 13th International Congress on Mathematical

Education, ICME-13 Monographs, DOI 10.1007/978-3-319-62597-3_127
} 
Du Sautoy (2008) tried to capture the creative nature of mathematics in an interview in the Guardian newspaper:

I think very often the exciting moments in mathematical history are moments when suddenly there's a leap of imagination - for example, the idea of negative numbers, or zero-I mean, that's almost as imaginary as a four-dimensional shape. What's a negative number? I can't show you minus three potatoes - but let's come up with the idea of a negative number and the way that it will behave and explore that. That's why it's a creative subject. It's a lot about creative intuition...in Einstein's view, the ultimate test for an equation was an aesthetic one. The highest praise for a good theory was not that it was correct or that it was exact, simply that it should be beautiful.

Thus, by integrating mathematics and music in a truly interdisciplinary way, we can support children to explore patterns and relationships in ways that develop their creativity, understanding and aesthetic pleasure.

\section{References}

Barnes, J. (2015). Cross-curricular learning 3-14. London: Sage.

Burton, L. (1984). Mathematical thinking: The struggle for meaning. Journal for Research in Mathematics Education, 15(1), 35-49, 36.

Du Sautoy M. (2008). The Guardian Newspaper. November 3, 2008 [Online]. Available at: http:// www.theguardian.com/science/2008/nov/03/marcus-dusautoy

Hofstadter, D. R. (1979). Gödel, Escher, Bach: An eternal golden braid. London: Harvester.

Open Access Except where otherwise noted, this chapter is licensed under a Creative Commons Attribution 4.0 International License. To view a copy of this license, visit http://creativecommons. org/licenses/by/4.0/.

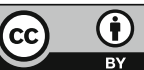

